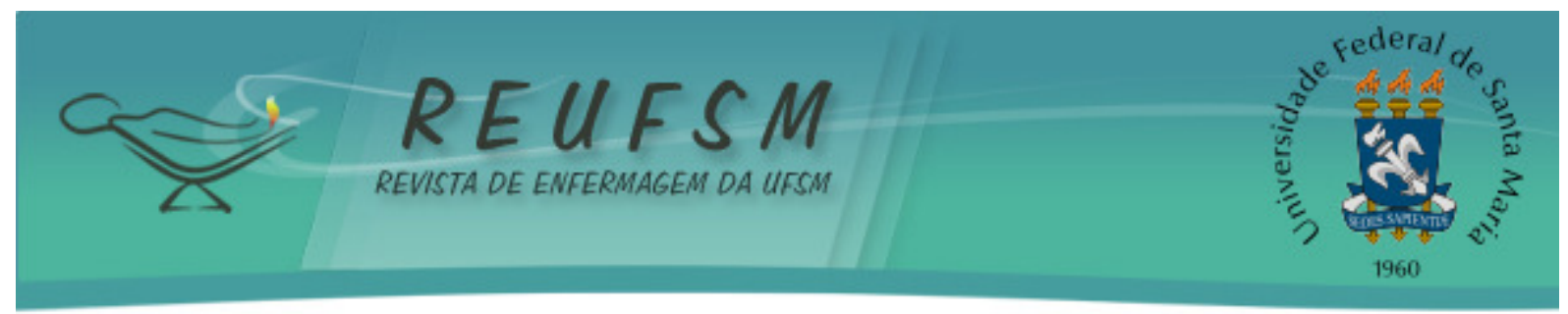

RELATO DE EXPERIÊNCIA

\title{
ABORDAGEM SOBRE A DISCIPLINA VIOLÊNCIA EM UM CURSO DE GRADUAÇÃO EM ENFERMAGEM
}

\section{APPROACH ABOUT A COURSE ON VIOLENCE IN A NURSING UNDERGRADUATE PROGRAM ABORDAJE SOBRE LA DISCIPLINA DE LA VIOLENCIA EN UN CURSO DE GRADUACIÓN DE ENFERMERÍA}

\author{
Daniella Yamada Baragatti ${ }^{1}$ \\ Celene Aparecida Ferrari Audi ${ }^{2}$ \\ Márcio Cristiano de Melo ${ }^{3}$
}

Doi: $10.5902 / 2179769211265$

RESUMO: Objetivo: descrever a experiência da inserção e do desenvolvimento de uma disciplina "Violência, Saúde e Gênero" em um curso de graduação em enfermagem. Método: relato de experiência fundamentado nas vivências como docente que ministrou a disciplina "Violência, Saúde e Gênero" na Faculdade de Jaguariúna (FAJ)- SP. Resultados: a disciplina específica sobre o tema possibilitou que os alunos falassem sobre o assunto, permitindo amplas discussões, sendo que muitos relataram experiências com suas diversas tipologias (autoinfligida, interpessoal, coletiva) e suas diferentes naturezas (física, sexual, psicológica, privação ou negligência), vivenciadas por eles ao longo da vida. Conclusão: introduzir a disciplina sobre a violência trouxe resultados positivos, pois possibilitaram amplas discussões e reflexões sobre o tema, desmistificação do assunto e melhor preparação dos futuros enfermeiros para lidar com a problemática.

Descritores: Violência; Ensino; Violência doméstica; Violência contra a mulher; Violência sexual.

ABSTRACT: Aim: to describe the experience of the inclusion and development of a course entitled "Violence, Health and Gender " in an undergraduate program of Nursing. Methods: experience report based on experiences as a professor who taught the course "Violence, Health and Gender" at the Faculty of Jaguariuna (FAJ) - SP. Results: the specific course on the topic enabled the students to talk about the subject, allowing wide discussions. Many of the students reported their experiences throughout life with different types of violence (self-inflicted, interpersonal, collective) and their different natures (physical, sexual, psychological, neglect or deprivation). Conclusion: introducing a course about violence has brought positive results, enabling extensive discussions and reflections on the topic, deconstruction of myths about the subject and better preparation for the future nurses to deal with the issue.

Descriptors: Violence; Teaching; Domestic violence; Violence against women; Sexual violence.

RESUMEN: Objetivo: describir la experiencia de la integración y el desarrollo de la disciplina "Violencia, Salud y Género", en un curso de graduación en enfermería. Método: relato de experiencia sobre los conocimientos adquiridos como docente de la asignatura "Violencia, Género y Salud" en la Facultad de Jaguariuna (FAJ) - SP. Resultados: la

\footnotetext{
${ }^{1}$ Docente da Faculdade de Jaguariúna, Enfermeira da Atenção Básica em Campinas-SP e Doutoranda da Faculdade de Enfermagem da Universidade Estadual de Campinas, SP, Brasil, e-mail: danybaragatti@gmail.com ${ }^{2}$ Enfermeira Pós-Doutoranda em Saúde Coletiva na Faculdade de Ciências Médicas da Universidade Estadual de Campinas, SP, Brasil, e-mail: celenefaudi@yahoo.com.br

${ }^{3}$ Enfermeiro Especialista em Saúde Coletiva pela UFMG, Mestrando em Saúde Coletiva pela Faculdade de Ciências Médicas da Universidade Estadual de Campinas, SP, Brasil, e-mail: enf.marciomelo@gmail.com
} 


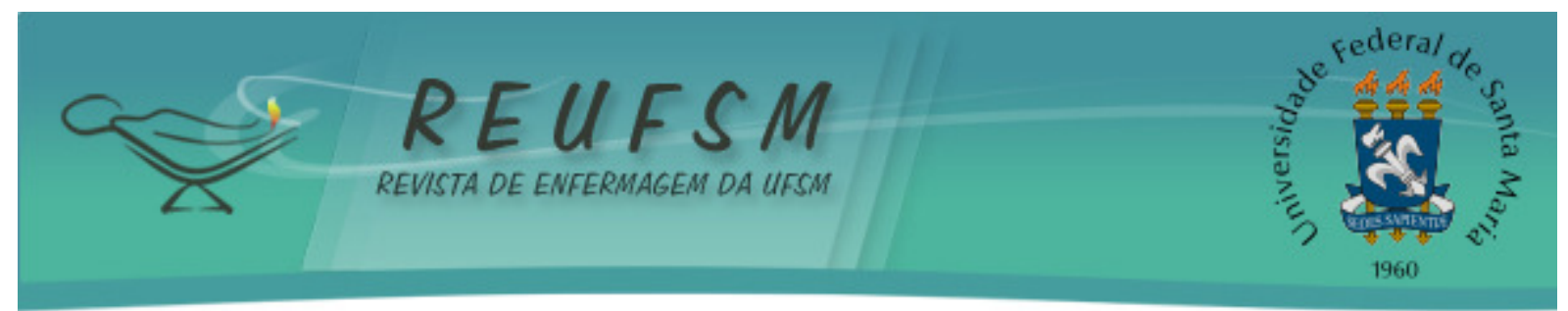

asignatura específica sobre el tema permitió a los estudiantes hablar sobre el tema, lo que hace posible un amplio debate, y muchos relataron sus experiencias con diversas tipologías (auto-infligida, interpersonal, colectiva) y sus diferentes naturalezas (física, sexual, psicológica, negligencia o privación) experimentadas por ellos durante toda la vida. Conclusión: introducir la asignatura sobre la violencia trajo resultados positivos, ya que permite amplios debates y reflexiones sobre el tema, desmistificación del asunto y una mejor preparación de las futuras enfermeras para enfrentar la problemática.

Descriptores: Violencia; Enseñanza; Violencia doméstica; Violencia contra la mujer; Violencia sexual.

\section{INTRODUÇÃO}

A violência acontece desde o início da existência humana, sob as mais diversas formas, sendo atualmente a principal causa de morte de pessoas entre 15 e 44 anos de idade. São gastos bilhões de dólares para cuidados com a saúde devido à violência, ou seja, podendo ser considerado um problema de saúde pública. ${ }^{1-2}$

Segundo dados da Organização Mundial de Saúde (OMS) apresentados no Relatório Mundial sobre Violência e Saúde, estima-se que, no ano 2000, morreram 1,6 milhões de pessoas no mundo inteiro devido aos diversos tipos de violência (autoinfligida, interpessoal ou coletiva), o que corresponde a 28,8 mortes violentas por 100 mil habitantes, sendo que a maior parte dessas mortes ocorreu em países de renda baixa. ${ }^{3-4}$

No Brasil, desde 1960, o quadro de mortalidade geral revela uma mudança com o processo de urbanização. A violência passa a ser um fenômeno relevante em detrimento da mortalidade por doenças infecto-parasitárias. A partir da década de 1980, as mortes por causas violentas passam a ser a segunda causa de morte no obituário geral, abaixo apenas das doenças cardiovasculares. É considerada, também no país, a primeira causa de óbito de pessoas entre 5 e 49 anos de idade, mortes essas que são prematuras, evitáveis e onerosas se pensarmos nos anos perdidos de vida. ${ }^{5-7}$ Os dados sobre os casos de morbidade por violência em nosso país são insuficientes, pois deve-se considerar também a mutilação de pessoas, custos financeiros e a demanda do setor saúde, e não somente os dados de mortalidade. ${ }^{8}$

Tradicionalmente esses eventos foram tratados como objeto exclusivo da segurança pública e somente a partir da década de 90 as organizações internacionais da área de saúde passaram a recomendar aos países membros, a inclusão da violência e dos agravos dela decorrentes, como temas para sua agenda de intervenção. ${ }^{3}$

A resolução da 49a Assembleia Mundial da Saúde (World Health Assembly) de 1996 declara a violência como um dos principais problemas de saúde pública, no mundo. ${ }^{9}$ Segundo a Organização Mundial de Saúde:

Violência é o uso intencional da força física ou do poder, real ou por ameaça, contra a própria pessoa, contra outra pessoa, ou contra um grupo ou comunidade que pode resultar, ou tem alta probabilidade de resultar, em morte, lesão, dano psicológico, problemas de desenvolvimento ou de privação. ${ }^{10: 5}$

Essa definição contém dois conceitos centrais, a intencionalidade e o efeito ou dano do evento violento em suas vítimas, sendo esses os pilares nos quais o setor saúde tem se apoiado para sustentar a necessidade de investigar e propor intervenções preventivas desse flagelo social e de saúde. ${ }^{11}$

A compreensão da violência exige reconhecimento de que a mesma se constitui como um fenômeno mundial, histórico e multifatorial, entrelaçado tanto nas questões macrossociais 


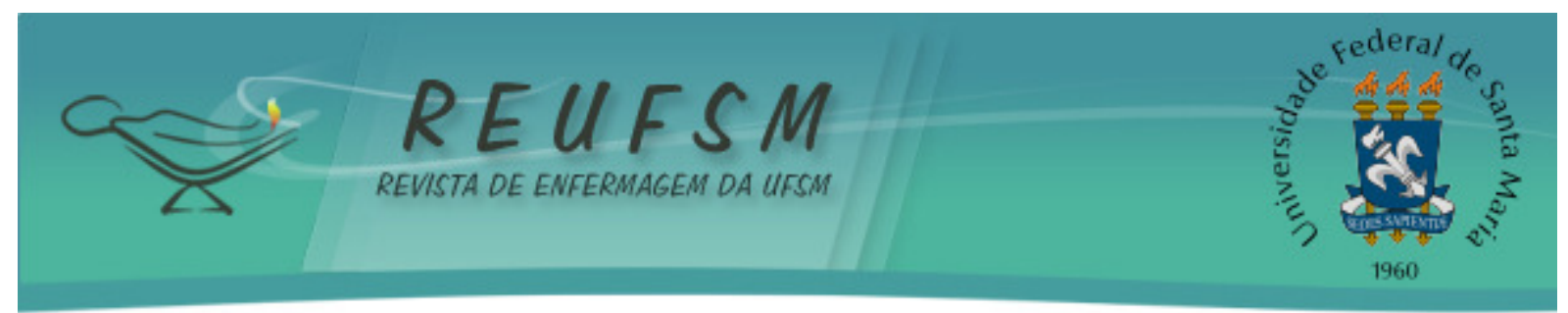

quanto estruturais. A violência gera embates e controvérsias entre os vários campos do saber, muito em decorrência dos múltiplos significados dados a palavra e traduzidos, por aquele autor, como "polissemia de repertórios" ao se discursar sobre esse tema. Esta pluralidade de significados impõe a necessidade de interpretarmos a violência em suas várias faces e de nos apoiarmos para a intervenção, fundamentalmente, na interdisciplinaridade. ${ }^{12}$

O Ministério da Saúde, responsável pela Política Nacional de Saúde, assinou um Acordo de Cooperação Técnica com o Ministério da Justiça visando ações conjuntas da Estratégia Saúde da Família e do Programa Nacional de Segurança Pública. Neste acordo consta que os profissionais de saúde devem estar capacitados para diagnosticar, tratar e contribuir para a prevenção da violência, uma vez que se encontram em posição estratégica para detectar os riscos da violência e identificar suas principais vítimas. ${ }^{13}$ Dentro desta lógica é recomendado que os profissionais estejam capacitados para lidar com as diferentes formas de violência. Para tanto, é de fundamental importância considerar a inserção desses temas, violência, saúde e gênero, nos currículos de graduação.

Em estudo sobre a inserção do tema violência intrafamiliar nos currículos de cursos de graduação em enfermagem e medicina de universidades públicas e particulares do Rio de Janeiro (RJ) e Cuiabá (MT) constatou-se que, na enfermagem, o tema é trabalhado sob o ponto de vista psicossocial e da promoção da saúde, enquanto que na medicina trabalha-se sob o ponto de vista biomédico vinculado ao trauma físico. Os autores destacaram que é preciso trabalhar com os alunos o desenvolvimento da consciência de forças sociais maiores que afetam a vida e a saúde da comunidade, dentre elas a violência como uma questão social. ${ }^{14}$

$\mathrm{Na}$ Universidade Federal de Santa Catarina foi realizada uma pesquisa com acadêmicos do último ano de cursos de graduação em enfermagem, medicina e odontologia. Os achados deste estudo revelaram que: a inserção do tema violência durante a formação aconteceu de forma esporádica e superficial, onde foram mais evidenciadas as agressões e os danos físicos quanto à manifestação dos atos violentos. Foi apontado que o profissional de saúde encontra dificuldade em identificar situações de violência quando presta assistência de forma superficial às vítimas; e um último achado foi referente à formação acadêmica, concluindo que esta não discute o tema suficientemente. ${ }^{15}$

Em estudo para avaliar o conteúdo "violência por parceiro íntimo" no currículo de enfermeiros cursando pós-graduação em enfermagem em uma universidade americana encontraram, após aplicação de um questionário, que os estudantes de enfermagem que receberam treinamento sobre violência por parceiro íntimo durante a graduação tiveram, significativamente, maior preparo e conhecimento sobre o assunto do que os que não tiveram tal tema abordado em sua formação. ${ }^{16}$

A enfermagem possibilita a construção de elos de confiança que permitem a reconstrução de conceitos sobre violência com a finalidade de reduzir os índices deste agravo e mudar a realidade social. Planejar para que seja efetivada uma assistência humanizada e com segurança para o cuidado, voltado para as necessidades individuais e coletivas. ${ }^{17}$

Tendo em vista a magnitude dos temas e a importância que os profissionais de saúde estejam capacitados para lidar com essas questões, este artigo tem como objetivo descrever a experiência da inserção e do desenvolvimento de uma disciplina "Violência, Saúde e Gênero" em um curso de graduação em enfermagem.

\section{MÉTODO}

Trata-se de relato de experiência da introdução de uma disciplina, obrigatória, específica sobre a violência, saúde e gênero, no curso de graduação em enfermagem da Faculdade de Jaguariúna (FAJ). 


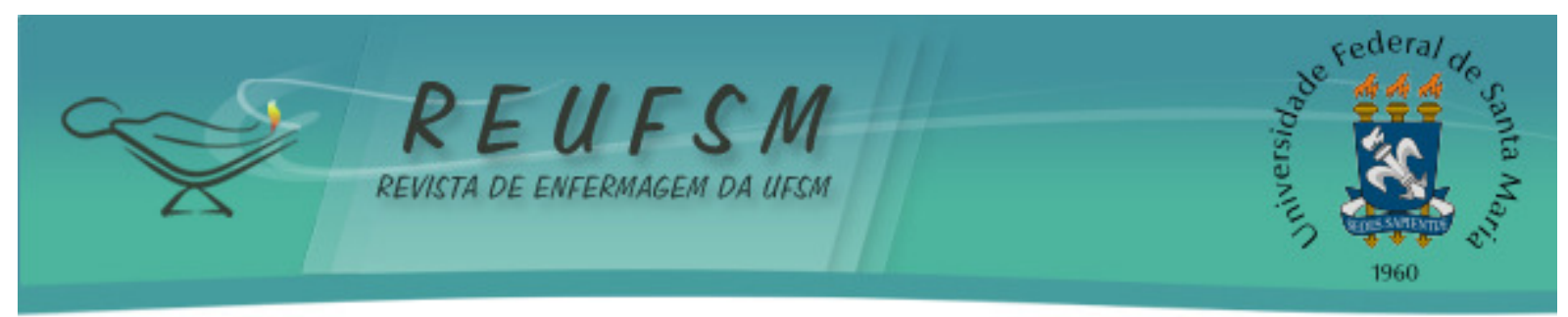

A FAJ é localizada no município de Jaguariúna, que fica a $120 \mathrm{Km}$ da capital do estado de São Paulo. É uma instituição de Ensino Superior mantida por uma entidade jurídica de direito privado, de fins educacionais. Possui atualmente 19 cursos de graduação em atividade, sendo que a graduação em enfermagem é um deles. ${ }^{18}$

0 Curso de Enfermagem da FAJ iniciou suas atividades no ano de 2002 sob autorização da Portaria Ministerial $n^{\circ}$. 2.870, de 14 de dezembro de 2001. Em junho de 2005, ano em que se formou a primeira turma de egressos, passou por avaliação externa do INEP/MEC, tendo seu reconhecimento formalizado através da Portaria Ministerial $n^{\circ}$. 3.469, de 05 de outubro de 2005. Algumas alterações foram realizadas na Matriz Curricular do Curso, entretanto, no ano de 2009 iniciou-se a discussão entre o corpo docente e discente sobre a Resolução CNE/CES №. 04, de 6 de Abril de 2009, que dispõe sobre Carga Horária Mínima e procedimentos relativos à Integralização na modalidade presencial do curso de Enfermagem - mínimo de 4000 horas - 5 (cinco) anos - 10 (dez) semestres letivos para integralização. Essas ações contribuíram para a reestruturação do Projeto Pedagógico do Curso (PPC), assim como com a construção da nova Matriz Curricular (MC) que passou de 8 para 10 semestres.

Algumas estruturações foram discutidas e implementadas, modificadas e implantadas no curso. Dentre essas, a inclusão da "Disciplina Violência, Saúde e Gênero" que, no ano de 2013 começou a ser ministrada, com carga horária de 40 horas semestrais, para os alunos que cursam o $7^{\circ}$ semestre.

O Projeto Pedagógico e a nova Matriz Curricular foram construídos Coletivamente, de forma inovadora, criativa e flexível, respeitando as realidades local e regional, tendo como arcabouço teórico o Sistema Único de Saúde, a Ética, a Cidadania, a Epidemiologia, e o Processo Saúde Doença e o Cuidado.

A disciplina aborda os principais conceitos de violência, saúde e gênero. Possibilita o conhecimento dos aspectos epidemiológicos e sua dinâmica na saúde pública, assim como as políticas públicas que tratam desses temas. Tem como principais objetivos capacitar o aluno no entendimento dos aspectos epidemiológicos dos vários tipos de violência; conceituar gênero e sua relacão com a saúde; entender o papel do setor saúde em relacão aos vários tipos de violência. Como trabalho discente efetivo foi solicitado ao aluno a leitura e resenha do livro Carcereiros (Drázio Varella), e que possibilitou debate em sala de aula, assim como, as experiências de vida e das aulas práticas vivenciadas pelos alunos com a temática da disciplina.

Para alcançar tais objetivos, utilizaram-se metodologias ativas na disciplina. As metodologias ativas são aquelas em que o aluno é ativo no processo ensino-aprendizagem; consideram que o educador deve incentivar a capacidade crítica do educando sobre a prática e, ao refletir sobre a prática, os educandos podem se tornar agentes de mudança na sociedade. ${ }^{19}$ Considerou-se que seria importante facilitar os relatos de experiências trazidos pelos alunos, possibilitando tornar o processo formativo mais próximo das necessidades de saúde e à indissociabilidade entre as bases biológicas e sociais da atenção à saúde/enfermagem. Portanto, foram utilizados vídeos, filmes, discussão de reportagens divulgadas na mídia, leitura de textos, estudos de casos, sempre seguidos de intensas discussões.

Considerando os três eixos temáticos que compõem a disciplina: Contextualização sobre violência, saúde e gênero; Aspectos Conceituais da Violência; Ações de Saúde, relatamos nossa experiência no desenvolvimento dessa disciplina com os discentes.

\section{RELATO DE EXPERIÊNCIA}

Houve reflexão sobre a importância de o docente incentivar os alunos a participarem ativamente das aulas, baseado em publicação já existente, o que é um desafio aos professores acostumados a uma educação tradicional, destacando que para tal 


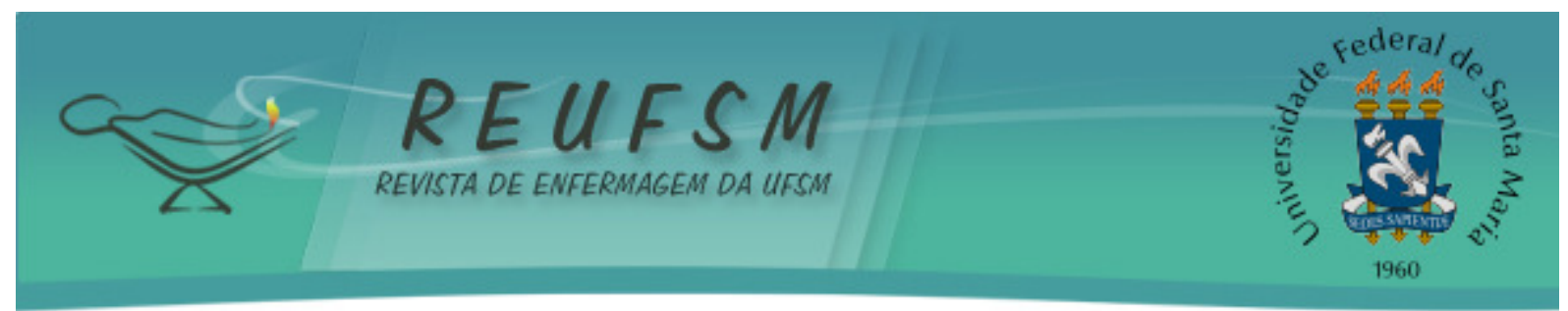

é necessário que haja escolha das técnicas de ensino adequadas, dependendo do que se pretende ensinar e com quais objetivos. ${ }^{20}$

A disciplina propiciou a discussão de questões culturais que influenciam a ocorrência de violência presentes nas falas dos alunos. Por exemplo, ao ser solicitado que relatassem um caso de violência contra a mulher presenciado por eles, os alunos contaram de uma jovem que apanhou do namorado na escola, na frente de todo mundo. Houve falas como "a menina apanhou, e ela ainda nem tinha feito nada!", como se, caso ela tivesse feito algo, fosse direito do namorado agredi-la. A violência de gênero é definida por um tipo de dominação, opressão e crueldade presente e reproduzido cotidianamente, nas relações sociais, pelos papéis atribuídos aos homens e às mulheres, ou seja, a mulher é vitimizada por haver situações aceitáveis pelo papel social inferior a ela em relação ao homem. ${ }^{21-23}$ Assim, dessa fala, discutiu-se a violência de gênero, e que nada daria o direito do parceiro agredi-la, que nada justifica uma situação de violência.

A violência na sociedade integra sua natureza onde se transmite a todos os espaços sociais, tais como: serviços públicos e privados, nas ruas e até mesmo dentro de casa. O tema violência não entrou no setor saúde de forma natural, ele se consolidou e o fez por muitos fatores. Os profissionais da saúde olharam para esse fenômeno emergente como um expectador, um ditador de eventos e um desfecho final para conflitos sociais. ${ }^{24}$

No Relatório Mundial sobre Violência e Saúde da OMS há a descrição dos diferentes tipos de violência, segundo as características daqueles que cometem o ato violento. A tipologia é apresentada em três categorias: autoinfligida (mutilação e suicídio); interpessoal (violência intrafamiliar e doméstica - abuso infantil, juvenil, contra idosos, violência praticada por parceiros íntimos, em grupos institucionais como escolas, locais de trabalho, prisões e asilos) e coletiva (social, política e econômica - inclui ações terroristas e guerras). Quanto à natureza dos atos violentos, há a violência física, sexual, psicológica e envolvendo privação ou negligência. ${ }^{1,25}$

Logo nas primeiras aulas, ao iniciar as discussões sobre as tipologias da violência e a natureza dos atos violentos houve muita surpresa, por parte da maioria dos alunos, pela violência autoinfligida ser considerada um tipo de violência. Então uma aluna relatou que quando era adolescente praticava violência autoinfligida, que era depressiva, e aquilo era um grito de socorro, que ninguém fazia nada, até que um profissional de saúde, médico, chamou a atenção da família para isso, e foi então que a família entendeu o problema e começou a ajudar e cuidar. Então, a aluna relatou a importância do profissional de saúde estar atento a esses sinais, pois é possível salvar vidas se houver atenção nesses casos.

Para iniciar as discussões sobre a relação entre o uso de substâncias e a violência passou-se uma reportagem disponível na internet que demonstrava um caso de abandono de uma etilista. Surgiram diversas discussões sobre o assunto, dentre elas, as questões familiares no caso. Então uma aluna relatou sua experiência com o pai, etilista crônico, que a família cuidou até o fim da vida, sendo que a negligência por parte da família seria, na opinião dela, inadmissível, pois a violência cometida pelo pai (etilista) não justificava outra violência (a negligência). Relatou a violência institucional vivenciada quando tinha que levar o pai ao hospital, pois os profissionais de saúde o tratavam mal "já que era bêbado". Emocionou-se e chorou ao descrever sua experiência, e enfatizou para os colegas a importância de não cometerem esse tipo de violência quando forem profissionais.

Houve surpresa da maioria dos alunos ao se discutir o Estatuto do Idoso e a violência que os idosos sofrem. Ao se discutir esse assunto, mais uma vez uma aluna relatou sua angústia e vivência pessoal: contou que sua avó estava com demência senil, relatou as dificuldades da família, pois havia parte dos familiares que eram negligentes no caso, e o quanto havia olhares de reprovação por parte de profissionais de saúde quando sua avó precisava de atendimento, ou seja, também sofria violência institucional. 


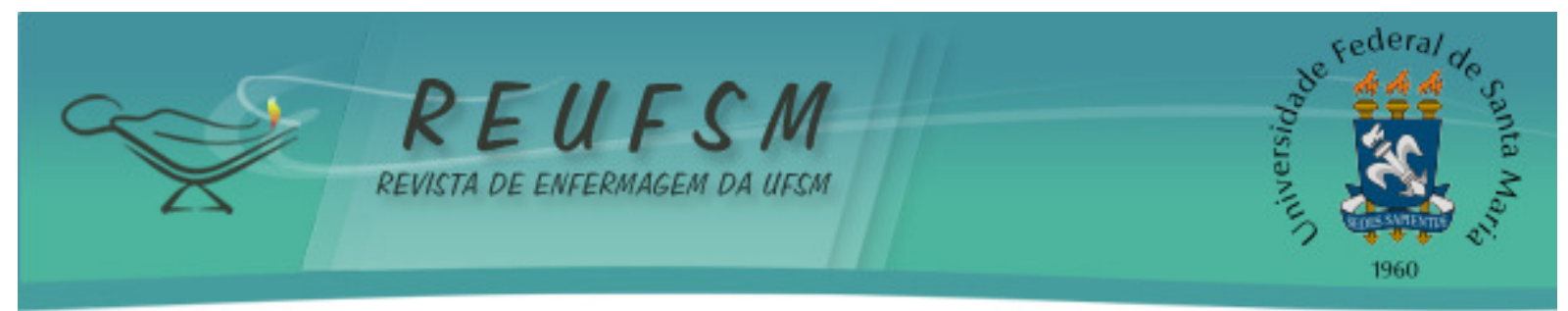

O fato de ministrar uma disciplina sobre violência encorajou alguns alunos a procurarem a docente responsável no fim da aula para contar suas experiências. Uma aluna relatou que sofria violência física e psicológica por parte de um ex-namorado, e que chegou a abandonar outro curso de graduação em outra instituição, pois ele a agredia fisicamente na frente de todos; destacou que, se na época alguém tivesse ao menos ouvido suas queixas (como era muito discutido nas aulas, a importância de se ouvir quem sofre violência), tinha convicção que teria deixado a situação muito antes.

No primeiro dia de aula, quando solicitado que descrevessem um caso de violência que tivessem vivenciado, uma aluna contou uma história de violência contra a mulher. Meses depois, já no fim da disciplina, a aluna procurou a docente responsável pela disciplina e contou que, na verdade, a história relatada no primeiro dia de aula havia acontecido com ela. Contou que sofreu violência física e psicológica pelo ex-marido, e que na época buscou ajuda em um serviço de saúde, mas não houve ajuda ou acolhimento; então reforçou o quanto era importante haver uma disciplina para discutir sobre a violência, para que os profissionais de saúde estejam realmente preparados para ouvir e auxiliar nos casos.

Houve ainda uma terceira aluna que procurou a docente no fim da aula, para mais uma vez contar que sofreu violência sexual dentro de casa (não quis comentar quem era o agressor). Referiu que reconhecia a importância do tema ser abordado na graduação, mas que sentia mal estar nas aulas, principalmente ao assistir um documentário sobre a violência sexual contra crianças, algo que a fazia lembrar-se de suas vivências. Mas destacou que era importante que trabalhássemos o tema, pois caso o assunto não surgisse na graduação, ela provavelmente "fugiria" de casos de violência enquanto profissional de saúde.

\section{CONSIDERAÇÕES FINAIS}

A introdução de uma disciplina específica sobre a violência no curso de graduação em enfermagem teve resultados positivos, pois propiciou amplas discussões sobre o tema, permitindo que surgissem vivências pessoais dos alunos e desmistificação do assunto.

Encontrou-se como limitações dessa experiência a dificuldade por parte de alguns alunos em dividir suas histórias, que, em alguns casos, eram de cunho pessoal reprimindo, às vezes, o discente na tentativa de se expressar e trazer a tona vivências passadas que de certa forma foram impactantes em sua vida.

Espera-se contribuir com a ampliação da abordagem do tema nos cursos de graduação em enfermagem, como a relação de cuidado entre o enfermeiro e usuário do serviço de saúde, de forma que possibilite, à população, buscar recursos que são disponíveis para a prevenção de novos casos. A vivência enquanto aluno possibilitará refletir na atuação enquanto profissional de enfermagem com vistas à transformação de uma situação de violência.

\section{REFERÊNCIAS}

1. Krug EG, Mercy JA, Dahlberg LL, Zwi AB. The world report on violence and health. Lancet [Internet]. 2002 out [acesso em 2013 maio 1];360(9339):1083-8. Disponível em: http://download.thelancet.com/pdfs/journals/lancet/PIIS0140673602111330.pdf?id=8b69a badd6dadf97:5f43b62c:142054b4c29:618b1383073863421 doi: 10.1016/S01406736(02)11133-0.

2. Dantas RAN, Farias GM, Rocha KMM, Costa IKF, Medeiros RC. O impacto da violência na saúde pública: uma revisão de literatura. Rev Enferm UFPE Online [Internet]. 2010 nov-dez [acesso em 2014 fev 17];4(Esp):1935-43. Disponível em: http://www.revista.ufpe.br/revistaenfermagem/index.php/revista/article/viewFile/1480/ pdf_253. 


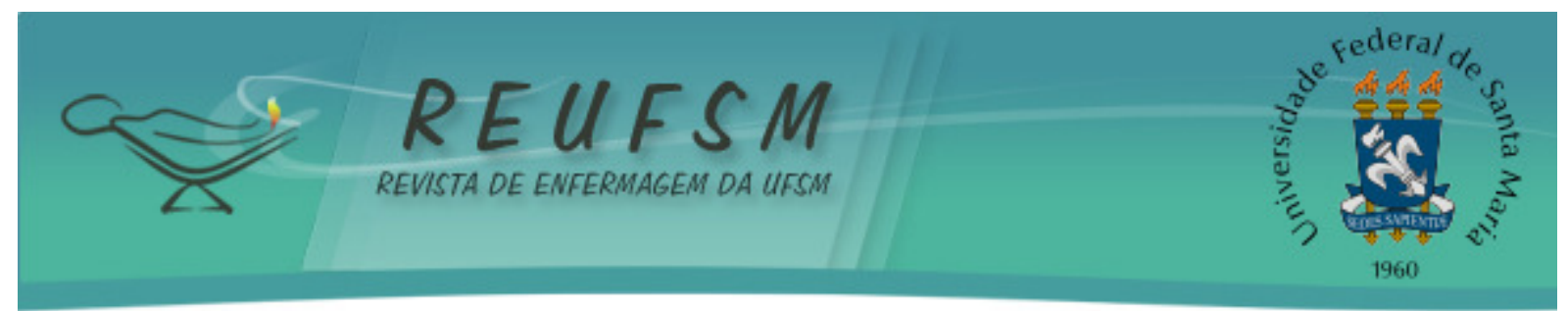

3. World Health Organization (WHO). Multi-country study on women's health and domestic violence against women [Internet]. Geneva; 2005 [acesso em 2013 maio 1]. Disponível em: http://www.who.int/gender/violence/who_multicountry_study/en/.

4. Organización Mundial de la Salud (OMS). Departamento Género y Salud de la Mujer. Grupo Salud Familiar y de la Comunidad. Dando prioridad a las mujeres: recomendaciones éticas y de seguridad para la investigación sobre la violencia doméstica contra la mujer [Internet]. Suiza, Ginebra: OMS; 2001 [acesso em 2013 maio 1]. Disponível em: http://whqlibdoc.who.int/hq/2001/WHO_FCH_GWH_01.1_spa.pdf.

5. Minayo MCS. A violência social sob a perspectiva da saúde pública. Cad Saúde Publica [Internet]. 1994 [acesso em 2013 maio 1];10 Supl 1:7-18. Disponível em: http://www.scielo.br/pdf/csp/v10s1/v10supl1a02.pdf.

6. Minayo MCS, Souza ER. Violência e saúde como um campo interdisciplinar e de ação coletiva. Hist Cienc Saude Manguinhos [Internet]. 1998 [acesso em 2013 maio 1];4(3):51331. Disponível em: http://www.scielo.br/pdf/hcsm/v4n3/v4n3a06.

7. Minayo MCS, Souza ER. É possível prevenir a violência? Reflexões a partir do campo da saúde pública. Cienc Saude Coletiva [Internet]. 1999 [acesso em 2013 maio 1];4(1):7-32. Disponível em: http://www.scielo.br/pdf/csc/v4n1/7127.pdf. http://dx.doi.org/10.1590/S1413-81231999000100002.

8. Desalandes SF. O atendimento às vítimas de violência na emergência: "prevenção numa hora dessas? Cienc Saude Coletiva [Internet]. 1999 [acesso em 2013 maio 1];4(1):81-94. Disponível em: http://www.scielo.br/pdf/csc/v4n1/7132.pdf. http://dx.doi.org/10.1590/S1413-81231999000100007.

9. Forty-Ninth World Health Assembly (WHA). Resolution of the World Health Assembly: Prevention of violence, a public health priority [Internet]. Geneva; 1996 [acesso em 2013 maio 1]. Disponível em: http://www.who.int/violence_injury_prevention/publications/violence/en/.

10. Organização Mundial de Saúde (OMS). Relatório mundial sobre violência e Saúde. Genebra: OMS; 2002.

11. Concha-Eastman A. Relatório mundial sobre a violência e a saúde da OMS: uma resposta ao desafio das violências. Rev Saúde (CNS). 2002;3(3):12-3.

12. Camarnado Júnior DV, Villela WV. A polissemia do conceito de violência. Bol Instituto Saúde. 2004;33:8-10.

13. Brasil. Ministério da Saúde. Secretaria de Atenção à Saúde. Departamento de Atenção Básica. Por uma cultura da paz, a promoção da saúde e a prevenção da violência. Brasília: Ministério da Saúde; 2009. $1^{\text {a }}$ ed. p. 36.

14. Souza ER, Penna LHG, Ferreira Al, Tavares CMM, Santos NC. O tema violência intrafamiliar em currículos de graduação em enfermagem e medicina. Rev Enferm UERJ [Internet]. 2008 fev-mar [acesso em 2014 fev 17];16(1):13-9. Disponível em: http://www.facenf.uerj.br/v16n1/v16n1a02.pdf.

15. Rosa R, Boing AF, Schraiber LB, Coelho EBS. Violência: conceito e vivência entre acadêmicos da área da saúde. Interface Comun Saúde Educ [Internet]. 2010 jan-mar [acesso em 2014 fev 17];14(32):81-90. Disponível em: http://www.scielo.br/pdf/icse/v14n32/07.pdf. 


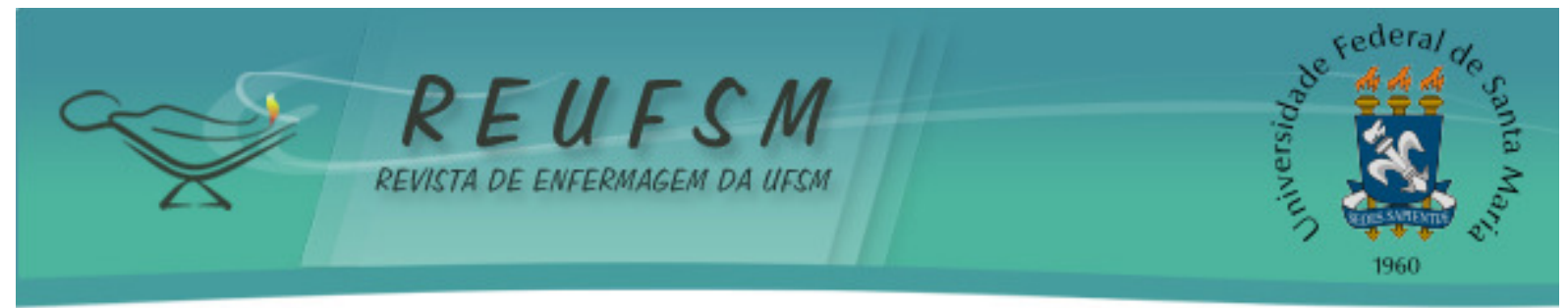

16. Connor PD, Nouer SS, Speck PM, Mackey SN, Tipton NG. Nursing students and intimate partner violence education: improving and integrating knowledge into health care curricula. J Prof Nurs [Internet]. 2013 jul-ago [acesso em $2014 \mathrm{fev}$ 17];29(4):233-9. Disponível em: http://www.professionalnursing.org/article/S8755-7223(12)00116-0/pdf. doi: 10.1016/j.profnurs.2012.05.011.

17. Aguiar RS. O cuidado de enfermagem à mulher vítima de violência doméstica. Rev Enferm Cent O Min [Internet]. 2013 maio-ago [acesso em $2014 \mathrm{fev}$ 17];3(2):723-31. Disponível em: http://www.seer.ufsj.edu.br/index.php/recom/article/view/358/436.

18. Faculdade de Jaguariúna FAJ). Histórico. Jaguariúna; 2013 [acesso em 2013 jul 8]. Disponível em: http://www.faj.br/f.aspx?id=45.

19. Freire $P$. Pedagogia da autonomia: saberes necessários à prática educativa. $25^{\mathrm{a}}$ ed. São Paulo: Paz e Terra; 2002. Não há docência sem discência. p. 12-8.

20. Bordenave JD, Pereira AM. Estratégias de ensino-aprendizagem. $28^{\mathrm{a}}$ ed. Petrópolis: Vozes; 2007.

21. Minayo MCS. Violência e saúde. Rio de Janeiro: Editora Fiocruz; 2006.

22. Labronici LM, Ferraz MIR, Trigueiro TH, Fegadoli D. Perfil da violência contra mulheres atendidas na Pousada de Maria. Rev Esc Enferm USP [Internet]. 2010 [acesso em $2014 \mathrm{fev}$ 17];44(1):126-33. Disponível em: http://www.scielo.br/pdf/reeusp/v44n1/a18v44n1.pdf. doi: $10.1590 /$ S0080-62342010000100018.

23. Santi LN, Nakano AMS, Lettiere A. Percepção de mulheres em situação de violência sobre o suporte e apoio recebido em seu contexto social. Texto \& Contexto Enferm [Internet]. 2010 jul-set [acesso em $2014 \mathrm{fev}$ 17];19(3):417-24. Disponível em: http://www.scielo.br/pdf/tce/v19n3/a02v19n3.pdf. doi: 10.1590/s010407072010000300002.

24. Lisboa MTL, Moura FJM, Reis LD. Violência do cotidiano e no trabalho de enfermagem: apreensões e expectativas de alunos de um curso de graduação em enfermagem do Rio de Janeiro. Esc Anna Nery Rev Enferm [Internet]. 2006 abr [acesso em 2013 jul 18];10(1):81-6. Disponível em: http://www.scielo.br/pdf/ean/v10n1/v10n1a10.pdf. doi: 10.1590/S141481452006000100010.

25. Minayo MCS. A inclusão da violência na agenda da saúde: trajetória histórica. Cienc Saude Coletiva [Internet]. 2007 [acesso em 2013 jul 18];11 Sup:1259-67. Disponível em: http://www.scielo.br/pdf/csc/v11s0/a15v11s0.pdf. doi: 10.1590/S141381232006000500015.

Data de recebimento: $02 / 11 / 2013$

Data de aceite: $24 / 07 / 2014$

Contato com o autor correspondente: Daniella Yamada Baragatti

Endereço postal: Faculdade de Enfermagem - Universidade Estadual de Campinas. Rua Tessália Vieira de Camargo, 126. Cidade Universitária "Zeferino Vaz". CEP: 13083-887. Campinas, SP, Brasil.

E-mail: danybaragatti@gmail.com 